\title{
INTENSIDADE DE QUEIMA DE DIFERENTES RETARDANTES DE FOGO ${ }^{1}$
}

\author{
Nilton Cesar Fiedler², Weslen Pintor Canzian³ ${ }^{3}$, Reginaldo Gonçalves Mafia ${ }^{4}$, Guido Assunção Ribeiro ${ }^{5}$ e \\ Jair Krause Junior ${ }^{3}$
}

\begin{abstract}
RESUMO - Esta pesquisa objetivou avaliar o efeito de diversos tipos de retardantes de fogo e dosagens na eficiência de combate aos incêndios florestais. $\mathrm{O}$ experimento foi realizado em mesa de combustão, em laboratório com quatro tipos de retardantes de fogo (WD 881, RFC-88, F-500 e HMIS 1-0-0 DPnb) em três concentrações $(0,5 \% ; 1 \%$; e $1,5 \%)$, além de testemunha com água. A dosagem de calda da mistura de retardante com água utilizada foi de $0,5 \mathrm{~L}$ por metro quadrado de área. Para a análise, foi medido o tempo que o fogo levou para consumir a área com a aplicação do produto e a distância entre o início da parcela e o local onde o fogo se extinguiu. Durante a queima de cada parcela (tratamento/repetição), foram avaliadas as seguintes variáveis: umidade relativa, velocidade do vento, tempo gasto para o fogo queimar a parcela com e sem o produto e a distância que o fogo avançou na parcela com o produto. Os retardantes com maior eficiência foram o F-500, HMIS 1-0-0 DPnb e WD 881, que apresentaram diferença significativa pelo teste de Tukey a 5\% de probabilidade, diferenciando-se da testemunha e do RFC-88. A concentração mais eficiente foi a de $1,5 \%$, com as menores taxas de inflamabilidade em todos os casos.
\end{abstract}

Palavras-chave: Retardante de fogo; Inflamabilidade; Eficiência.

\section{INTENSITY OF BURNING FLAME IN DIFFERENT FIRE RETARDANTS}

\begin{abstract}
This research aimed to evaluate the effect of different types of fire retardants and dosages in the efficiency of fighting forest fires. The experiment was conducted in combustion table in the laboratory with 4 types of flame retardants (WD 881, RFC-88, F-500 and HMIS 1-0-0 DPnB) at 3 concentrations (0.5\%, $1 \%$ and $1.5 \%$ ) plus water as control. The dosage of the tail of the retardant mixture with water was 0.5 liter per square meter of area. For the analysis it was measured the time that it took to the fire to consume the area with the application of the product and the distance between the top of the parcel and the location where the fire was extinguished. During the firing of each plot (treatment / repeat) the following variables were evaluated: relative humidity, wind speed, time spent by the fire to burn the plot with and without the product and the distance advanced by the fire in the parcel with the product. Retardants with greater efficiency were F-500, HMIS 1-0-0 DPnB and WD 881, that showed significant differences by Tukey test at 5\% probability, differentiating the control and the RFC-88. The most effective concentration was $1.5 \%$ with the lowest levels of flammability in all cases.
\end{abstract}

Keywords: Fire retardant; Inflammability; Efficiency.

\footnotetext{
${ }^{1}$ Recebido em 26.08.2014 aceito para publicação em 15.05.2015.

${ }^{2}$ Universidade Federal do Espírito Santo, Centro Agropecuário, Departamento de Engenharia Florestal, Alegre, ES - Brasil. E-mail: <fiedler@pq.cnpq.br>.

${ }^{3}$ Universidade Federal do Espírito Santo, UFES, ES - Brasil.E-mail: <weslenpcanzian@hotmail.com>e $<$ krausejunior@hotmail.com>

${ }^{4}$ Centro de Tecnologia, Fibria Celulose S.A., Aracruz, ES - Brasil. E-mail: <rgoncalves@fibria.com.br>.

${ }^{5}$ In memoriam.
}

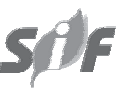

Revista Árvore, Viçosa-MG, v.39, n.4, p.691-696, 2015 http://dx.doi.org/10.1590/0100-67622015000400011 


\section{INTRODUÇÃO}

O fogo contribuiu muito para a evolução e desenvolvimento da humanidade. O seu domínio em épocas primitivas proporcionava maior segurança e conforto. Com o passar dos anos, os povos passaram a desenvolver metodologias de obtenção do fogo, não se restringindo apenas aos fatores naturais.

O que foi motivo de conforto e segurança em épocas primitivas passou a ter restrições nos tempos modernos. O fogo utilizado em grande escala e constantemente é um agente potencialmente destruidor e poluidor.

Um dos grandes problemas enfrentados pelas empresas florestais em grande parte do planeta são os incêndios florestais. Esses incêndios, na maior parte das vezes, são criminosos, em que há a intenção de propagar o fogo por plantios florestais.

De acordo com Fiedler (2006) e Soares e Batista (2007), os incêndios florestais geram diversos prejuízos, sendo eles econômicos, paisagísticos e ambientais, podendo ocorrer nas mais variadas localidades. Existem, hoje em dia, diversas técnicas de prevenção e combate aos incêndios florestais. Os métodos utilizados na prevenção são, muitas vezes, não suficientes para evitar as ocorrências. Dessa maneira, o aprimoramento das técnicas e métodos de combate aos sinistros vem sendo cada vez mais importantes para evitar perdas no meio florestal.

Uma das maiores dificuldades encontradas no combate aos incêndios florestais é a obtenção de água. Esse recurso, que se encontra cada vez mais escasso, muito das vezes se encontra em regiões distantes dos incêndios e de difícil disponibilidade, o que torna a atividade de alto custo. Dessa maneira, é de fundamental importância o estudo de produtos químicos que melhorem a eficiência da água na fase de combate.

Retardante de fogo é um composto químico que, utilizado puro ou misturado com água, proporciona redução ou eliminação da queima de determinado material combustível (RIBEIRO et al., 2006).

Os retardantes químicos podem ser classificados de distintas maneiras, e a mais utilizada e conhecida é com base no tempo de duração em que o retardante fica ativo (PASTOR FERRER, 2004). Dessa forma, são comumente rotulados em dois tipos: Retardantes de curta duração - que agem meramente pela intensificação da habilidade de amortização da água, através da maior fixação desta pelo comburente ou pelo retardamento da evaporação, ou ambos. São caracterizados por serem produtos espumógenos e viscosantes. Retardantes de longa duração - sua ação ocorre mesmo após toda a água ter sido evaporada sobre o material combustível, em que os resíduos dos agentes inibidores ficam fixados exercendo a função de mitigar a ação do fogo ou, até mesmo, extingui-lo. No grupo desses agentes químicos estão incluídos todos os produtos retardantes à base de sais de amoníaco, como: sulfatos, fosfatos e polifosfatos (BATISTA et al., 2008).

Uma vantagem do uso desses retardantes de fogo é a capacidade de aumentar a eficiência do uso da água com um custo relativamente baixo (SANT'ANNA et al., 2007).

O uso de produtos químicos que melhoram a eficiência da água na extinção do fogo ou que possam substituí-la aumenta à medida que alarga a dificuldade em se obter água e aumenta a intensidade do incêndio (BATISTA, 2009).

O objetivo desta pesquisa foi avaliar o efeito de diversos tipos de retardantes de fogo e dosagens na eficiência de combate aos incêndios florestais.

\section{MATERIAL E MÉTODOS}

\subsection{Local de estudo}

O projeto de avaliação de diferentes concentrações de distintos retardantes de fogo foi realizado no mês de setembro de 2012, nas dependências do Laboratório de Incêndios Florestais e de Conservação da Natureza do Departamento de Engenharia Florestal da Universidade Federal de Viçosa.

\subsection{Procedimento de trabalho}

O substrato utilizado como material combustível, para receber as diferentes concentrações dos retardantes objetos do estudo, foi padronizado, e todas as parcelas foram montadas com capim-gordura (Mellinis minutiflora) seco, na quantidade de $2,50 \mathrm{~kg}$ de material combustível por metro quadrado. Em todas as parcelas, essa massa de $2,50 \mathrm{~kg}$ de capim-gordura era uniformemente distribuída sobre a mesa de combustão.

A quantidade de calda utilizada nesta pesquisa foi de $0,5 \mathrm{~L}$ por metro quadrado, em diferentes concentrações $(0,5 \% ; 1,0 \%$; e $1,5 \%)$ dos diferentes tipos de retardantes analisados. $\mathrm{O}$ teste foi realizado 
em uma mesa experimental sem declividade, com parcelas de 0,5 x 2,0 m de dimensão. As dosagens, com as diferentes concentrações, foram aplicadas na metade das parcelas $(0,5 \times 1 \mathrm{~m})$, sendo pulverizados $250 \mathrm{ml}$ de calda, de forma homogênea.

Foram montadas 39 parcelas, sendo 12 tratamentos com três repetições, além de uma testemunha, com água, com três repetições. Os tratamentos foram representados pela utilização dos diferentes produtos (WD 881, RFC88, F-500 e HMIS 1-0-0 DPnb).

Todos os produtos utilizados nesta pesquisa são classificados como retardantes de longa duração, ou seja, sua ação prevalece mesmo após a evaporação da água sobre a superfície do material combustível. Apesar de os produtos serem de longa duração, o princípio ativo os diferenciou, em que o WD 881 é uma mistura de fosfato de amônio com sulfato de amônio; o RFC-88 tem como princípio ativo o polifosfato de amônio; o F-500 utiliza uma tecnologia encapsuladora, em que um agente Umectante proporciona a redução da tensão superficial do material combustível; e o HMIS 1-0-0 DPnb é constituído de tensoativos de hidrocarbonetos com propilenoglicol.

Para determinação da umidade, da quantidade de matéria seca e do poder calorífico, foram retiradas cinco amostras do material combustível com $2,50 \mathrm{~kg}$ e, em seguida, secas em estufa a $65^{\circ} \mathrm{C}$ até peso constante.

Antes de ser dada a ignição em um dos lados da parcela, era aplicada de forma homogênea a mistura de retardante de fogo com água no espaço destinado $(0,5 \mathrm{~m} \times 1 \mathrm{~m})$. A linha de fogo era acesa em uma das extremidades da parcela (sem o produto), de forma que o fogo percorresse na direção do local com o produto aplicado. A distância queimada referiu-se, apenas, à extensão que o fogo percorreu na parte da parcela com os retardantes. A parte da parcela sem os produtos serviu apenas para a linha de fogo se estabelecer (Figura 1).

Durante a queima de cada parcela (tratamento/ repetição) foram realizadas as seguintes medições: velocidade do vento, tempo gasto para o fogo queimar a parcela sem o produto, tempo gasto para o fogo queimar a parcela com o produto e a distância que o fogo avançou na parcela com o produto.

Pelo fato de a pesquisa ter sido realizada em condições laboratoriais, foi possível obter controle e homogeneidade sobre alguns fatores ambientais, que são comumente variáveis e, muito das vezes, incontroláveis em situações de campo. O vento é uma das variáveis que mais podem influenciar sobre o efeito da ação dos retardantes, visto que a sua intensidade, frequência e direção possivelmente alterariam os resultados, podendo, dessa forma, desfavorecer algum produto, consequentemente tornando os resultados imprecisos.

A intensidade de queima foi determinada pela equação de Byram (1959). A intensidade de queima é uma variável utilizada na caracterização do comportamento do fogo e está diretamente associada à reação da combustão. Por ter relação direta com a velocidade de propagação do fogo, resulta no fato de que, quanto mais rápido o avanço do fogo, maior a quantidade de energia liberada para o ambiente e mais rapidamente acontece a combustão do material. Com a presença dos diferentes tipos de retardantes, espera-se que a reação da combustão sofra interferências, pois o objetivo desses produtos químicos é interromper ou dificultar a combustão.

A intensidade de queima é dada pela seguinte equação: I = H.w.r, em que I é a intensidade de queima, dada em $\mathrm{kcal} / \mathrm{m} / \mathrm{s}$; H é o poder calorífico do material

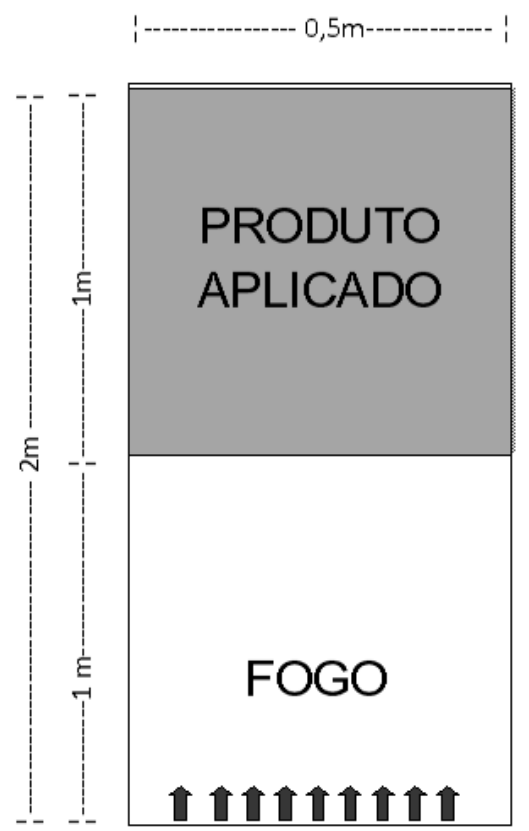

Figura 1 - Esquema ilustrativo do local de aplicação do fogo e do retardante.

Figure 1 - Illustrative scheme of the application site and fire retardant.

Revista Árvore, Viçosa-MG, v.39, n.4, p.691-696, 2015 
combustível, dado em kcal; w é a carga de material combustível disponível, dado em $\mathrm{kg} / \mathrm{m}^{2}$; e r é a velocidade de propagação do fogo, dada em $\mathrm{m} / \mathrm{s}$.

\subsection{Análises estatísticas}

Com os dados experimentais obtidos, foi avaliada a normalidade dos erros pelo teste de Shapiro-Wilk. Em seguida, os dados foram submetidos à análise de variância. Quando o valor de "F" foi significativo, as médias dos tratamentos foram submetidas à comparação de médias por meio do teste de Tukey a $5 \%$ de probabilidade de erro. As médias dos tratamentos quantitativos foram submetidas à análise de regressão linear. Os resultados são as médias originais obtidas.

\section{RESULTADOS}

A quantidade de material combustível utilizado, sua umidade, altura e densidade estão demonstradas pelas respectivas médias na Tabela 1 . De acordo com a classificação de Brown (1974), o material combustível estudado se enquadra na menor classe de espessura e diâmetro, variando de 0-0,6 cm.

Nas Tabelas 2 e 3 são mostrados a análise da variância e o efeito dos diferentes produtos sobre a intensidade de queima, respectivamente.
Considerando o propósito da metodologia deste estudo, a análise da regressão linear, avaliando as concentrações dos produtos, foi expressa pela equação $y=101.6569-69.6864 x$, com $^{2}$ de 0,612.

Conforme a representação gráfica da regressão linear (Figura 2), observou-se que, à medida que a concentração dos produtos aumentou, as intensidades de queima diminuíram.

\section{DISCUSSÃO}

A quantidade de material combustível total utilizada nesta pesquisa é de $2,5 \mathrm{~kg} \cdot \mathrm{m}^{-2}$, o que corresponde a 25 t.ha $^{-1}$. Esse valor se aproxima da realidade encontrada em incêndios florestais, visto que, de acordo com Rego e Botelho (1990), a quantidade de material combustível em florestas pode variar de 20 a 100 t.ha ${ }^{-1}$.

A densidade do material combustível utilizada correspondeu a 1,77 do trabalhado por Batista et al. (2008). Essa condição de alta densidade, associada ao diâmetro do material combustível inferior a $6 \mathrm{~mm}$, foi determinante para propagação do fogo, de acordo com Botelho e Fernandes (1999), proporcionando queimas de altas intensidades e podendo, dessa forma, avaliar a eficiência dos retardantes e suas concentrações.

A ação dos retardantes se dá sobre a reação da combustão e afeta diretamente o comportamento

Tabela 1 - Valores médios da massa do material combustível, umidade, altura e densidade.

Table 1 - Average values of the mass of combustible material, humidity, height and density.

\begin{tabular}{ccccccc}
\hline & $\begin{array}{c}\text { Total } \mathrm{MC}^{*} \\
\text { úmido }\left(\mathrm{kg} \cdot \mathrm{m}^{-2}\right)\end{array}$ & $\begin{array}{c}\text { Total MC*seco } \\
\left(\mathrm{kg} \cdot \mathrm{m}^{-2}\right)\end{array}$ & $\begin{array}{c}(\%) \text { de } \\
\text { umidade }\end{array}$ & $\begin{array}{c}\text { Total MC* } \\
\text { seco t.ha }\end{array}$ & $\begin{array}{c}\text { Altura MC* } \\
(\mathrm{cm})\end{array}$ & $\begin{array}{c}\text { Densidade } \\
\left(\mathrm{kg} \cdot \mathrm{m}^{-3}\right)\end{array}$ \\
\hline Média & 2,50 & 2,21 & 13,12 & 25,00 & 15,00 & 16,66 \\
\hline
\end{tabular}

$* \mathrm{MC}=$ material combustível.

Tabela 2 - Resultados da análise de variância da intensidade de queima em quatro produtos de retardantes químicos do fogo submetidos a diferentes concentrações.

Table 2 - Results of the analysis of variance for burning intensity of four products of chemical fire retardants subjected to different concentrations.

\begin{tabular}{lcc}
\hline Fonte de variação & G.L & Quadrado médio (significância) \\
\hline Produto & & Intensidade de queima \\
Concentração & 3 & $693.0192 *$ \\
Produto*Concentração & 2 & $2159.0028^{*}$ \\
Média & 6 & $110.1253^{\mathrm{ns}}$ \\
$\mathrm{R}^{2}$ & - & 57.4089 \\
\hline
\end{tabular}

ns não significativo a $5 \%$ de probabilidade; * F significativo a $5 \%$ de probabilidade; e $\mathrm{R}^{2}$ coeficiente de determinação.

Revista Árvore, Viçosa-MG, v.39, n.4, p.691-696, 2015 
Tabela 3 - Intensidade de queima $\left(\mathrm{kcal} \cdot \mathrm{m}^{-1} \cdot \mathrm{s}^{-1}\right)$ de quatro retardantes químicos do fogo e da testemunha com água.

Table 3 - Intensity of burning $\left(\mathrm{kcal} . \mathrm{m}^{-1} \cdot \mathrm{s}^{-1}\right)$ for four chemical fire retardants and treatment with water.

\begin{tabular}{cc}
\hline Produto & Intensidade de queima $\left(\mathrm{kcal} \cdot \mathrm{m}^{-1} \cdot \mathrm{s}^{-1}\right)$ \\
\hline 4 & $69.406 \mathrm{a}$ \\
3 & $57.320 \mathrm{~b}$ \\
2 & $54.296 \mathrm{~b}$ \\
1 & $48.613 \mathrm{~b}$ \\
Testemunha & $77.514 \mathrm{a}$ \\
\hline
\end{tabular}

*Médias seguidas pela mesma letra na coluna não diferem entre si, pelo teste de Tukey a 5\% de probabilidade.

Produto 4: RFC-88; 3: F-500; 2: HMIS 1-0-0 DPnb; e 1:WD 881.

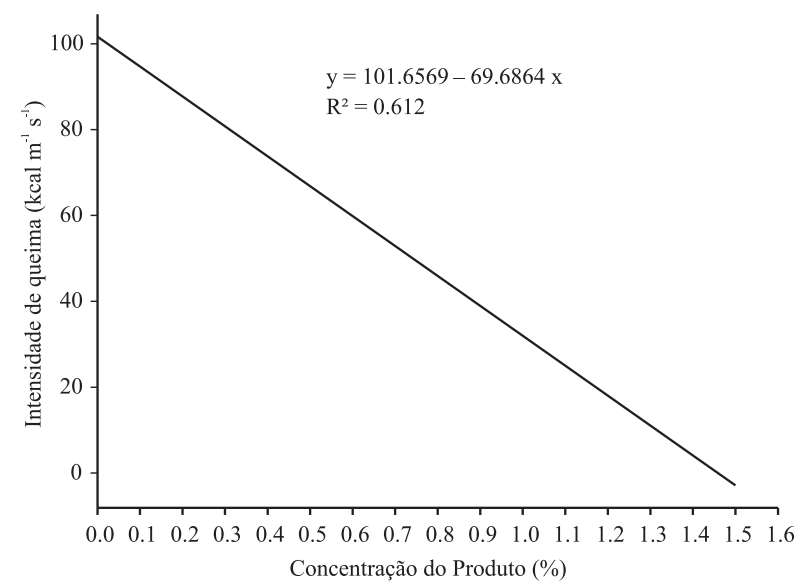

Figura 2 - Intensidade de queima $\left(\mathrm{kcal} \cdot \mathrm{m}^{-1} \cdot \mathrm{s}^{-1}\right)$ em diferentes concentrações do produto.

Figure 2 - Intensity of burning $\left(\mathrm{kcal} . \mathrm{m}^{-1} \cdot \mathrm{s}^{-1}\right)$ at different concentrations of product.

do fogo, o qual tem no cálculo da intensidade de queima uma das formas mais clássicas para a sua compreensão.

A intensidade da linha de fogo mostrou resultados dentro do esperado, uma vez que o que se deseja de um retardante é diminuir a intensidade de queima. Com destaque apareceu o WD881, com redução de 37,28\% da testemunha apenas com água.

Comparando os retardantes, através da análise de variância da intensidade de queima, pode-se verificar, na Tabela 2, que os produtos 1,2 e 3 se destacaram com as menores intensidades de queima, não diferenciando estatisticamente entre si. Entretanto, houve diferença significativa com os tratamentos da testemunha e do produto 4 .
Apesar de o produto WD881 não se ter diferenciado estatisticamente a $5 \%$ de probabilidade pelo teste de Tukey, do HMIS 1-0-0 DPnb e do F-500 nas condições em que o trabalho foi realizado, indica-se o seu uso, visto que, quanto menor a intensidade de queima de um incêndio, mais fácil tende a ser o seu controle.

Pode-se perceber, na Figura 2, que, quanto maior a concentração utilizada, menor a intensidade de queima. Com os dados obtidos, pode-se observar que a melhor concentração foi de $1,5 \%$.

\section{CONCLUSÕES}

De acordo com esta pesquisa, pode-se perceber que a eficiência dos retardantes foi comprovada em todos os casos, visto que a sua função é diminuir a intensidade de queima. Seu efeito foi mais bem evidenciado nos retardantes F-500, HMIS 1-0-0 DPnb e WD 881, que reduziram, significativamente a $5 \%$ de probabilidade, a intensidade do fogo. Pela análise de regressão, pode-se observar que a concentração de maior eficiência foi de $1,50 \%$, por apresentar as menores taxas de inflamabilidade.

É de suma importância a replicação deste estudo em áreas florestais, para consolidar a eficiência do uso de retardantes de fogo, visto que as variações encontradas em campo podem influenciar nos resultados.

\section{REFERÊNCIAS}

BATISTA, A.C. et al. por BATISTA, A. C.; MARTINI, A.; PEREIRA, J. F.; FERREIRA, J. Avaliação da eficiência de um retardante de longa duração, à base de polifosfato amônico, em queimas controladas em condições de laboratório. Scientiae Forestalis, v.36, p.223-229, 2008.

BATISTA, A.C. O uso dos retardantes no combate aéreo aos incêndios florestais. Revista Floresta, v.39, p.5-10, 2009.

Botelho, H ; FERnANDES, P. Manual de uso do fogo na gestão de matos. Vila Real. Universidade de Trás-os-Montes e Alto Douro, 1999.59p.

BROWN, J.K. Handbook for inventorying downed woody material. Ogden:

Revista Árvore, Viçosa-MG, v.39, n.4, p.691-696, 2015 
Intermountain Forest and Range Experiment Station, 1974. p.1-24. (General Technical Report, INT-16).

BYRAM, G.M. Combustion of forest fuels. In: DAVIS, K.P. Forest fire - control and use. New York: Mc Graw Hill, 1959. p.77-84.

FIEDLER, N. C.; RODRIGUES, T. O.; MEDEIROS, M. B. Avaliação das condições de trabalho, treinamento, saúde e segurança de brigadistas de combate a incêndios florestais em unidades de conservação do Distrito Federal: estudo de caso. Revista Árvore, v.30, n.1, p.55-63, 2006.

PASTOR FERRER, E. Contribució a l'estudi dels efectes dels retardants en l'extinció d'incendis forestals. 2004.

304f. Tese (Doutorado em Engenharia Industrial)

- Centre de Estudis del Risc tecnològic,

Departament d'Enginyeria Química, Escola
Tècnica Superior d'Enginyeria Industrial de Barcelona, Barcelona, 2004.

REGO, F.R.; BOTELHO, H.S. Técnica do fogo controlado. Trás-os-Montes e Alto Douro: Universidade de Trás-os-Montes e Alto Douro, 1990. 124p.

RIBEIRO, G.A.; LIMA, G.S.; OLIVEIRA, A. L.S.; CAMARGOS, V.L.; MAGALHÃES, M.U. Eficiência de um retardante de longa duração na redução da propagação do fogo. Revista Árvore, v.30, n.6, p.1025-1031, 2006.

SANT'ANNA, C.M.; FIEDLER, N.C.; MINETTE, L.J. Controle de incêndios florestais. Alegre, ES: Suprema, 2007. 152p.

SOARES, R.V.; BATISTA, A.C. Incêndios florestais - Controle, efeitos e uso do fogo. Curitiba: 2007. 250p. 